\title{
Diagnosis and keys of the main dipterous families and species collected from rabbit and guinea pig carcasses in Cairo, Egypt
}

\author{
Rabab F. Sawaby*, Hayam El Hamouly and Reham H. Abo-El Ela
}

\begin{abstract}
Background: In the current study, 23 species within 18 genera and 13 families of order Diptera were taxonomically studied. These members were collected from, on, in, around and beneath the carcasses of rabbits and guinea pigs.

Results: The families which collected from the carcasses are as follows: Agromyzidae (one subfamily, one genus and only one species), Calliphoridae (three subfamilies, three genera and sex species), Dolichopodidae (one subfamily, one genus and only one species), Drosophilidae (one subfamily, one genus and only one species), Ephydridae (one subfamily, one genus and only one species), Fanniidae (one genus and only one species), Muscidae (two subfamilies, three genus and four species), Phoridae (one subfamily, one genus and only one species), Piophilidae (one subfamily, one genus and only one species), Psychodidae (one subfamily, one genus and only one species), Sarcophagidae (two subfamilies, two genera and three species), Sphaeroceridae (one subfamily, one genus and only one species), and finally Ulidiidae (one subfamily, one genus and only one species). Only seven of which (Calliphoridae, Fanniidae, Muscidae, Phoridae, Piophilidae, Sarcophagidae and Ulidiidae) are of forensic importance or necrophagous. Other families are the following: Drosophilidae, Psychodidae, Agromyzidae, Dolichopodidae, Ephydridae, and Sphaeroceridae are of minor importance as forensic indicators.
\end{abstract}

Conclusions: Taxonomic keys for the adults which collected from the carcasses were constructed. Also diagnosis, synonyms, photographs and the forensic importance for the taxa were provided.

Keywords: House fly, Blow fly, Forensic entomology, Taxonomy, Cairo

\section{Background}

The members of order Diptera probably have a great economic impact on humans than any other group of insects. Some flies are pests of agricultural plants; others transmit diseases to humans and domestic animals. On the other hand, many flies are beneficial particularly those that pollinate flowering plants, serve as biocontrol agents of insect pests, or help in the decomposition of organic matter. True flies are one of the most important orders in forensic entomology. Maggots of various species visit corpses and carcasses at fairly well-defined times after the death of the victim. Thus, the presence or absence of particular species of fly maggots and other scavenger insects provide evidence as a basis for

\footnotetext{
* Correspondence: rabab_sawaby@yahoo.com

Entomology Department, Faculty of Science, Ain Shams University, Abassia, Cairo, Egypt
}

Springer Open

(c) The Author(s). 2018 Open Access This article is distributed under the terms of the Creative Commons Attribution 4.0 International License (http://creativecommons.org/licenses/by/4.0/), which permits unrestricted use, distribution, and reproduction in any medium, provided you give appropriate credit to the original author(s) and the source, provide a link to the Creative Commons license, and indicate if changes were made.

estimation of the time since death, and sometimes other details such as the place of death (Scudder \& Cannings, 2006 \& Carvalho \& Mello-Patiu, 2008).

Order Diptera is a large order containing about $1,000,000$ species, even though only $12 \%$ (about 125,000 species) have been described (Peter, 2007). Flies are minute to large insects (about 0.5 to $60 \mathrm{~mm}$ long), extremely variable in form and color, but are mostly rather soft bodied, flying forms. These insects are unique because their hind wings are reduced to small structures called halters. Adult flies live in a wide range of habitats and exhibit broad variation in appearance and life style. Dipteran larvae are generally more difficult to identify than the adults, they live in aquatic (fresh water), semiaquatic, or moist terrestrial environments (Unwin, 1981 and Scudder \& Cannings, 2006).

The aim of this study was to determine the dipterous species collected from carcasses of rabbits and guinea big 
in Cairo, Egypt, and construct taxonomic keys for different families, subfamilies, genera and species based on the essential morphological characters and genitalia in few species to facilitate the identification of carrion flies.

\section{Methods}

Samples of adult and immature stages collected from, on, in, around, and beneath the carcasses by sweep net, forceps, and spoons (for the larvae masses). Adult live specimens were killed, some were placed into a vial which is then put into a freezer $\left(-20{ }^{\circ} \mathrm{C}\right)$, while others were mounted on pins of different thicknesses according to their sizes and provided with labels indicating the date, then they were kept in preservative boxes supplied with naphthalene. Dead samples (if any) were also removed and maintained in a domestic freezer $\left(-20{ }^{\circ} \mathrm{C}\right)$. A small number of live Dipterous larvae and puparia were reared in small vials (larvae were fed rotten minced meat) at room temperature for confirmatory identification purposes. All the collected taxa were deposited in the Faculty of Science, Ain Shams University (ASUC). Male genitalia were dissected by putting them in $10 \%$ warm $\mathrm{KOH}$ solution for 10-15 min to macerate the abdomen; the rest of the dissected parts was preserved in $70 \%$ ethyl alcohol plus few drops of glycerin. The specimens were examined under a LABOMED, CZM4 dissecting, light binocular microscope. The photos were taken by a digital camera (Sony Dsc-W610).

Keys used for identification of dipterous families, genera and species according to: Al-Ghamdi et al, 2015; Bickel, 1985 and 2013; Brown et al, 2009; Brown \& Horan, 2012; Carles-Tolrá, 2011; Chen \& Kameneva, 2007; Couri, 2007; Couri et al, 2012; Disney, 1983; Draber-Monko et al, 2009; Ebrahim \& Salem, 2010; Emden, 1954; Haarto \& Kahannpää, 2013; Harrison, 1959; Huckett, 1975; James, 1947 and 1971; Ježek, 1977; Ježek et al, 2011; Kavazos \& Wallman, 2012; Keshavarzi et al, 2015; Kosmann et al, 2013; Kurahashi et al, 1997; Lopes, 1961; Marshall et al, 2011; Morgulis \& Freidberg, 2014; Nihei \& Barros De Carvalho, 2009; Oldroyd, 1954; Povolný \& Verves, 1997; Rochefort et al, 2015; Rohácek, 2011 and 2013; Shahid et al, 2000; Spencer, 1972 and 1977; Szpila, 2012; Vairo et al, 2011; Vilela, 1983 and Williams \& Villet, 2014.

\section{Results and discussion Key to the families} Useful for Diptera associated with carrion in the vicinity of Cairo, Egypt

1- Antennal flagellum with four or more segments which are usually uniform in shape and size, without apical stylus or arista; palpi usually with $3-5$ segments ..............................................Psychodidae

- Antennal flagellum consists of single segment, with apical stylus or arista; palpi with two or less segments (Fig. 2h).

.2

2- Ptilinal suture and lunule present (Fig. 2f, h)

- Ptilinal suture and lunule absent .3 12

3- Antennal pedicel with a complete dorsal seam; vibrissae usually present (Fig. 1p); greater ampulla present below wing base; calypters usually present (Fig. 2i). . .4

- Antennal pedicel usually without or with incomplete dorsal seam; vibrissae absent; greater ampulla absent; calypters usually small or undeveloped. .7

4- Meron with a vertical row of bristles......... .

- Meron without bristles. .6

5- Abdomen and usually thorax metallic blue or green in color (Fig. 1d, $\mathrm{f}, \mathrm{n}$ ). .Calliphoridae

- Abdomen dull gray, brown or black in color, sometimes shiny black (Fig. 3d, i, j).

\section{Sarcophagidae}

6- Wing with anal veins $\mathrm{A} 1$ and $\mathrm{A} 2$ convergent or nearly intersecting (Fig. 2d)

Fanniidae

- Wing with anal veins A1 and A2 nearly parallel or diverging (Fig. 2k)..................Muscidae

7- Hind tarsus with first tarsomere distinctly swollen and usually shorter than second tarsomere

Sphaeroceridae

- Hind tarsus with first tarsomere not swollen and longer than second tarsomere . .8

8- Subcosta complete or nearly so, ending at costa or just short of it and free from R1 distally.....

9

- -Subcosta incomplete, not reaching costa, often fusing with R1 distally . .11 

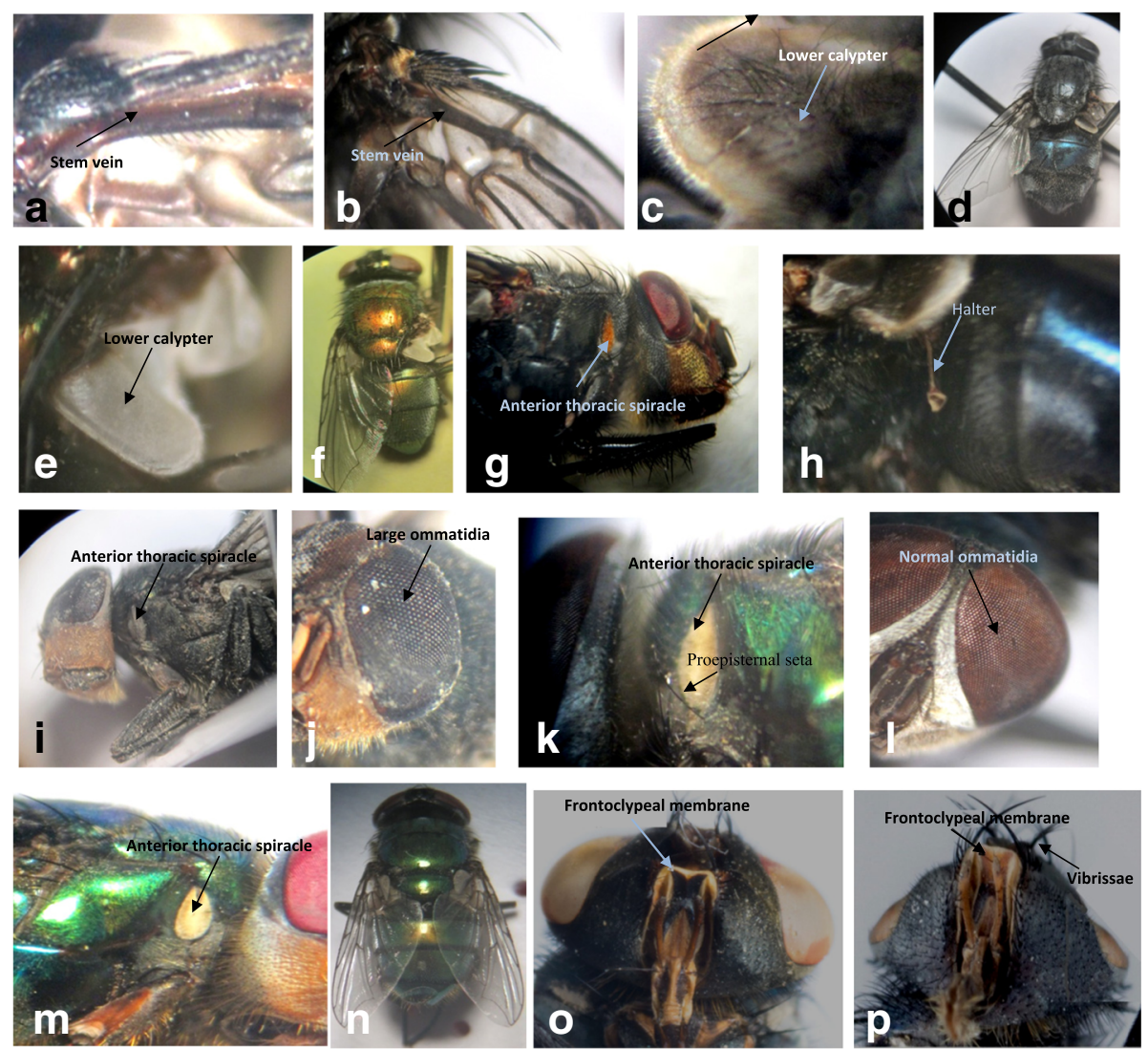

Fig. 1 a Chrysomya albiceps (Wiedemann, 1819), fore wing; b-d Calliphora vicina Robineau-Desvoidy,1830, b fore wing, c lower calypter, d adult; e, $\mathbf{f}$ Lucilia sericata (Meigen, 1826), e lower calypter, $\mathbf{f}$ adult; $\mathbf{g}, \mathbf{h}$ Calliphora vicina Robineau-Desvoidy, 1830, $\mathbf{g}$ anterior thoracic spiracle lateral view, $\mathbf{h}$ halter wing; $\mathbf{i}, \mathbf{j}$ Chrysomya megacephala (Fabricius, 1794) male, $\mathbf{i}$ anterior thoracic spiracle lateral view, $\mathbf{j}$ compound eye; k-I Chrysomya rufifacies (Macquart, 1842) male, $\mathbf{k}$ anterior thoracic spiracle lateral view, I compound eye; $\mathbf{m}, \mathbf{n}$ Chrysomya albiceps (Wiedemann, 1819), $\mathbf{m}$ anterior thoracic spiracle lateral view, $\mathbf{n}$ adult; o Lucilia cuprina (Wiedemann, 1830), head ventral view; $\mathbf{p}$ Lucilia sericata (Meigen, 1826), head ventral view

9- Wing with anal cell (cup) projected posteriorly as acute angular extension (Fig. 31); thorax color largely metallic blue-green

\section{Ulidiidae}

- Wing with anal cell (cup) rounded or truncate posteriorly; thorax color variable, not metallic blue-green.

10- Frons always with 3-5 strong inclinate frontal bristles which are relatively similar to the two reclinate orbital bristles in size and spacing......... Agromyzidae

- Frons seldom with any strong inclinate frontal bristles, but if one or two present they located distant from and inclined oppositely to the two lateroclinate orbital bristles
11- $\mathrm{CuA} 2$ and $\mathrm{A} 1$ absent or vestigial, never forming a closed cell cup; crossvein bm-cu absent, making cells $\mathrm{bm}$ and $\mathrm{dm}$ confluent

Ephydridae

- CuA2 and A1 present, always forming a closed cell cup; crossvein bm-cu usually present, making cells $\mathrm{bm}$ and $\mathrm{dm}$ usually separate.

Drosophilidae

12- Wing with branches of R strongly thickened and crowded into anterior base (Fig. 3b), and with four other weak and peculiarly aligned veins in remainder of wing blade; costa ending near middle of anterior margin.

\section{........Phoridae}

- Wing with branches of R not strongly thickened and crowded anterobasally, and with other veins normal; costa extending 

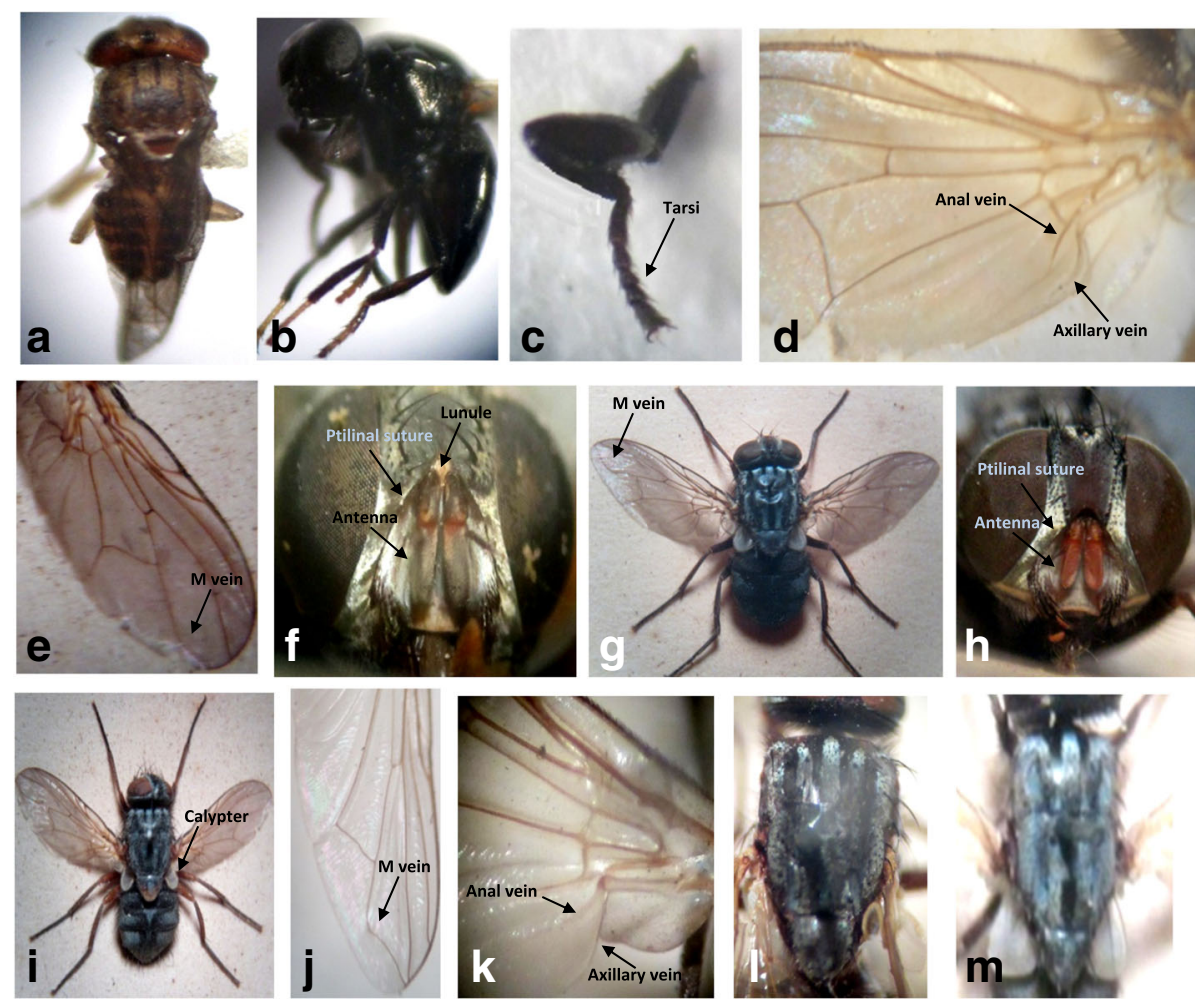

Fig. $\mathbf{2}$ a Drosophila repleta Wollaston, 1858, adult; b, c Chlorichaeta albipennis (Loew, 1848), b adult lateral view, c fore leg; d Fannia sp. fore wing; e, f, i Muscina stabulans (Fallén, 1817), e fore wing, f head frontal view, i adult; $\mathbf{g}, \mathbf{h}$ Synthesiomyia nudiseta (Van Der Wulp, 1883), $\mathbf{g}$ adult, $\mathbf{h}$ head frontal view; j-I Musca domestica (Linnaeus, 1758), j, k fore wing, I thorax dorsal view; m Musca sorbens (Wiedemann, 1830), adult

at least to wing apex.

..Dolichopodidae

1- Family: Agromyzidae Fallén, 1823

\section{Diagnosis}

Minute to small flies, ranged from 2 to $5 \mathrm{~mm}$ in length; usually blackish, grayish or yellowish in color. Head with distinctive sclerotization; vibrissae present and convergent; arista bare or with short hair; postocellar bristles divergent; one to seven frontal bristles present; upper part of frons above ptilinal suture slightly sclerotized and lacks setae; lower part of frons and dorsal area of head heavily sclerotized and setaceous; frontal vita often forms a distinctive patch on head different in color and texture to the rest of head. Wings usually hyaline, sometimes with dark markings in some species; costal vein with one break present at the apex of subcosta; subcosta faint; cell cup small; vein A1 not reached wing margin.

Subfamily: Phytomyzinae Fallén, 1810

Genus: Phytomyza Fallén, 1810

Phytomyza sp.

\section{Diagnosis}

Frons normal and not projecting. Antennae with third segment angulate. Costal vein extended to second and third radial vein $(\mathrm{R} 2+3)$; second cross vein absent; second costal section 2.5 times as long as the fourth; subcosta greatly reduced; costa ending at vein $R 4+5$. Hind margins of abdominal tergites may be partially yellow in color.

\section{2- Family: Calliphoridae Brauer \& Bergenstamm, 1889}

\section{Diagnosis}

Commonly shiny with metallic coloring, body ranging from 4 to $16 \mathrm{~mm}$ in length; frontal suture present which lies transversely above the antennae and extends downwards on each side thus presenting Ushaped form; antennae three-segmented with plumose arista beyond basal half, the second antennal segment distinctly grooved; ampulla large and calypters well developed; the thorax has continuous dorsal suture across the middle, along with well-defined posterior calli, meron with a row of bristles. The first 

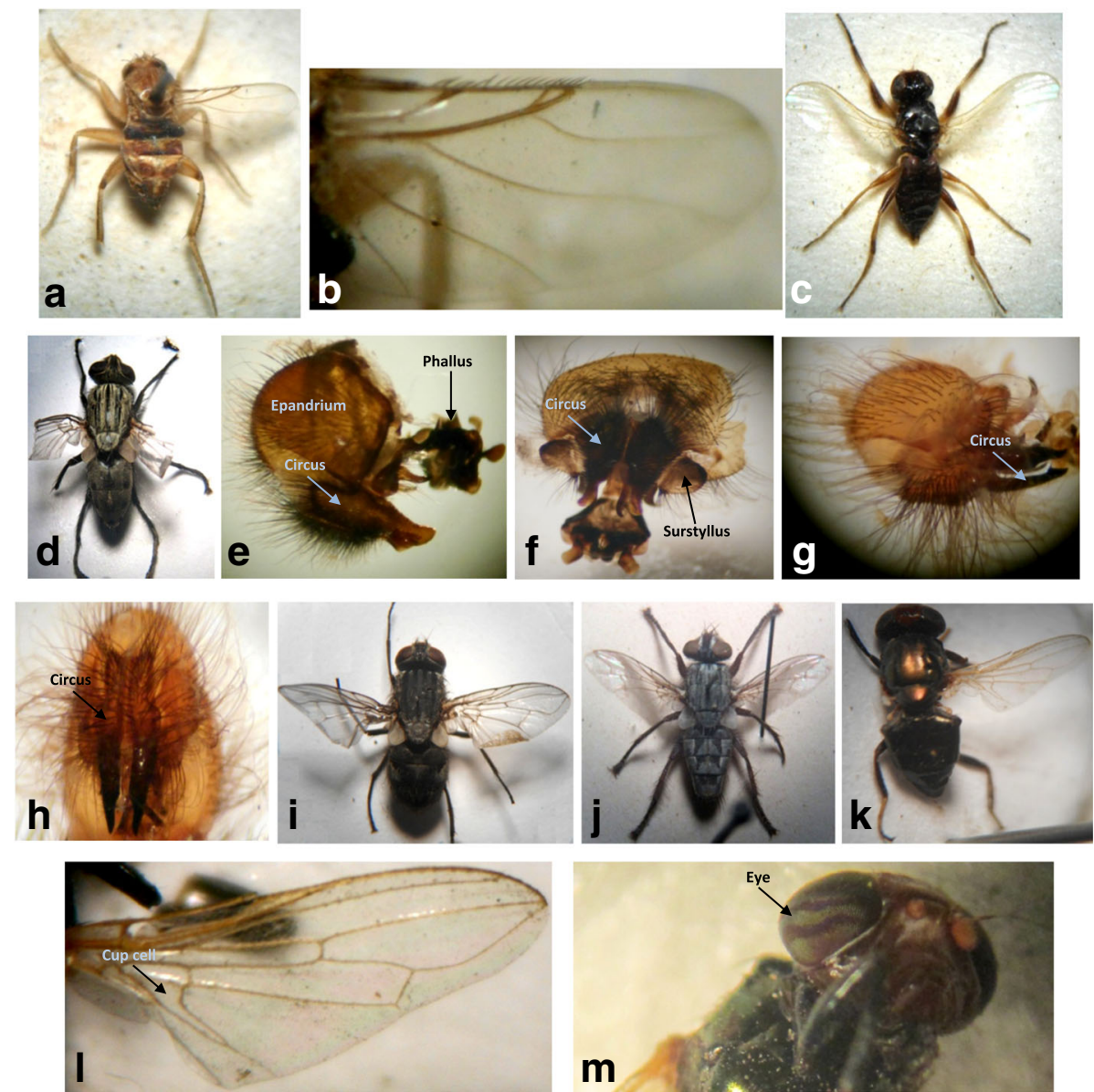

Fig. 3 a, b Megaselia scalaris (Loew, 1866), a adult, b fore wing; c Piophila casei (Linnaeus, 1758), adult; d Wohlfahrtia nuba (Wiedemann, 1830), adult; e, f, i Sarcophaga argyrostoma (Robineau-Desvoidy, 1830), e male genitalia lateral view, $\mathbf{f}$ caudal view, $\mathbf{i}$ adult; $\mathbf{g}, \mathbf{h}, \mathbf{j}$ Sarcophaga hertipes Weidemann, 1830, $\mathbf{g}$ male genitalia lateral view, h caudal view, $\mathbf{j}$ adult; k-m Physiphora alceae (Preyssler, 1791), $\mathbf{k}$ adult, I fore wing, $\mathbf{m}$ head lateral view

abdominal sternite overlaps the lateral margins of the tergites.

\section{Remark}

Calliphoridae or blow fly is one of the most forensically important families of insect. Members of calliphorid flies appeared on the carcasses usually at the early stages of decomposition, so, blow flies are very important organisms used in criminal investigations for estimation of postmortem interval (PMI). According to the trophic habitat, these species are classified as necrophagous (sarcophagous) insects devouring the soft moistened flesh of the decomposed bodies (Sharma, Garg, \& Gaur, 2015). In our study, six calliphorid species invaded carcasses usually at the fresh, bloated, and active decay stages of decomposition, whereas some individuals observed appearing during advanced decay and skeletal stages.

Formerly, Lucilia was included in the subfamily Chrysomininae, but currently it is considered in the Luciliinae (Marshall, Rohacek, Dong, \& Buck, 2011).

\section{Key to subfamilies}

1- Stem vein with bristles on the dorsal surface (Fig. 1a); ampulla reniform shape.

..Chrysomyinae Shannon

- Stem vein bare (Fig. 1b); ampulla oval in shape ...2

2- Dorsal surface of lower calypter hairy (Fig. 1c); thorax non-metallic, dark in color, abdomen subshining blue (Fig. 1d).

..Calliphorinae Brauer \& Bergenstamm

- Dorsal surface of lower calypter bare (Fig. 1e); thorax and abdomen bright green metallic, blue or bronze (Fig. 1f).

Luciliinae Shannon

1- Subfamily: Calliphorinae Brauer \& Bergenstamm, 1889

Genus: Calliphora Robineau-Desvoidy, 1830 
Calliphora vicina Robineau-Desvoidy, 1830

Calliphora vicina Robineau-Desvoidy, 1830.

Musca erythrocephala Meigen, 1826.

Calliphora monspeliaca Robineau-Desvoidy, 1830.

Calliphora scutellata Macquart, 1834.

Calliphora insidiosa Robineau-Desvoidy, 1863.

\section{Diagnosis}

Body 7-12 $\mathrm{mm}$ in length; head black on top and the front half of the cheek reddish orange, the lower region of the face black, frontal stripe black to brown, antennae black. Thorax black in color with four slightly marked dark stripes, dorsally with a dense grayish shine pubescence, acrostichal bristles present, the anterior thoracic spiracle orange in color. Hind coxae with a plate of fan bristles above near the posterior spiracles, which known as hypopleural bristles. Wings hyaline or a little tinged, darker at base with black veins, calypters brownish black, the lower one hairy with a white margin, halter dark brownish. Abdomen shining blue with black hairs.

2- Subfamily: Chrysomyinae Shannon, 1923

Genus: Chrysomya Robineau-Desvoidy, 1830

\section{Key to Species}

1. Anterior thoracic spiracle brown to dark brown in color (Fig. 1i); eye of male with only superior ommatidia large (Fig. 1j) C. megacephala

(Fabricius).

- Anterior thoracic spiracle whitish in color (Fig. 1k); eye of male with normal ommatidia (Fig. 11)

. .2 .

2. Proepisternal seta present (below anterior spiracles) (Fig. 1k). C. rufifacies (Macquart).

- Proepisternal seta absent (Fig. 1m). ..C. albiceps (Wiedemann)

1- Chrysomya albiceps (Wiedemann, 1819)

(Fig. 1a, m, n)

Musca albiceps Wiedemann, 1819.

Musca bibula Wiedemann, 1830.

Chrysomya albiceps: Dear, 1985.

\section{Diagnosis}

Body 7-12 mm in length. Antennae dark brown, third antennal segment about 3.5 times as long as the second one, arista brown, long plumose. Thorax greenish blue, anterior thoracic spiracles white, scutum with obscure marks behind the transverse suture, two narrow longitudinal stripes present anteriorly. Wing hyaline, basiocosta blackish, subcostal sclerite dark brown in color, calypters white, the lower one hairy on its upper surface. Legs black in color. Abdomen greenish blue, with purple reflection, first tergite black in male, greenish in female, second to fourth tergites usually black-banded in posterior margins.

\section{2- Chrysomya megacephala (Fabricius, 1794)}

(Fig. 1i, j)

Musca megacephala Fabricius, 1794.

Chrysomya megacephala Dear, 1985.

\section{Diagnosis}

Body 6-12 $\mathrm{mm}$ in length, stout. Head large, with prominent red eyes. Antennae brownish in color, third antennal segment about 3.7 times as long as the second one, arista dark brown, long plumose. Thorax greenish blue, pronotal region with three faint short stripes; calypters white, the lower one hairy on its upper surface. Legs black. Abdomen greenish blue

3- Chrysomya rufifacies (Macquart, 1842)

(Fig. 1k, l)

Lucilia rufifacies Macquart, 1842.

Chrysomya rufifacies Dear, 1985.

\section{Diagnosis}

Body 5-12 mm in length, shiny metallic blue-green in color. Frons twice the width of anterior ocellus in male; genal region white with whitish setae; outer vertical seta usually present in male; eye facets without clear line of separation between larger and smaller facets in male. Prothoracic spiracle pale; greater ampulla hairy; proepisternal seta present. Posterior margin of abdominal fifth tergite with cleft in female; first tergite and posterior margins of second and third tergites black in color.

3- Subfamily: Luciliinae Shannon, 1923

Genus: Lucilia Robineau-Desvoidy, 1830

\section{Key to species}

1. Body with copper coloration; humeral callus with two or three small setulae along posterior margin; frontoclypeal membrane dark brown to blackish (Fig. 10).

L. cuprina (Wiedemann).

- Body with metallic green or blue coloration; humeral callus with six to eight small setulae along posterior margin; frontoclypeal membrane light brown (Fig. 1p)............... L. sericata (Meigen)

1- Lucilia cuprina (Wiedemann, 1830) 
Musca cuprinaWiedemann, 1830.

Phaenicia pallescens Hall, 1948.

Lucilia cuprina Whitworth, 2006.

\section{Diagnosis}

Body 6-10 $\mathrm{mm}$ in length, rounded to oval metallic green with bronze/coppery reflections; eyes reddish. Antennae dark brown, third antennal segment two times as long as the second one. Thoracic spiracle black. Wing hyaline, upper calypter creamy white, lower one light brown. Halters dark brown. Middle tibia with antero-dorsal bristles. Abdomen metallic copper, with numerous black hairs.

2- Lucilia sericata (Meigen, 1826)

(Fig. 1e, f, p)

Musca sericataMeigen, 1826.

Phaenicia sericata Hall, 1948.

Lucilia sericata Whitworth, 2006.

\section{Diagnosis}

Body 6-10 $\mathrm{mm}$ in length, brilliant metallic, blue-green or golden coloration with black markings. Antennae black, third segment about three times as long as the second. Thorax with short, sparse black bristles and three cross-grooves. Wings clear with light brown veins, calypter white in color. Middle tibia with one anterodorsal bristle. Abdomen more or less oval.

3- Family: Dolichopodidae Latreille, 1809

\section{Diagnosis}

Small to medium slender flies; body length 1-9 mm; most species with greenish to blue metallic luster, while others dull yellow, brown or black in color. Eyes large and prominent. Antennae aristate. Ocellar bristles and outer vertical bristles well developed in most species. Legs long and slender. Wings clear or patterned with darker areas towards the wing margin; wing venation reduced; three radial veins $\mathrm{R} 1, \mathrm{R} 2+3, \mathrm{R} 4+5$ present; posterior basal cell and discoidal cell always fused; anal cell always small. Abdomen elongate-conical or flat; male genitalia often free and bear on a petiole; tergite 8 being asymmetrical.

Subfamily: Medeterinae Fischer von Waldheim, 1819 Genus: Medetera Fischer von Waldheim, 1819

Medetera sp.

\section{Diagnosis}

Relatively small flies; body $1.2-4.4 \mathrm{~mm}$ in length; usually dark metallic green to gray or black in color. Arista bare or lightly pubescent. Eyes large and widely separated in males and females. Mesoscutum greatly flattened. Wing usually hyaline; basal part of $\mathrm{M}$ vein curves down to $\mathrm{m}$ $\mathrm{cu}$ and arching up towards $\mathrm{R} 4+5$ to apex.

4- Family: Drosophilidae Róndani, 1856

\section{Diagnosis}

Small flies; body ranges from $2.5-4.5 \mathrm{~mm}$ in length; yellowish, golden, brownish or blackish in color. Eyes usually red in color; similar in size and shape in males and females. Arista plumose in many species with long hairs. Head with three strong frontal bristles on each side, one directed forward and the other two directed backward. Postocellar bristles convergent; vibrissae well developed. Costal vein with two to three breaks; subcostal vein incomplete; wing with small anal cell. Abdomen usually with seven spiracles in the female and six in the male.

Subfamily: Drosophilinae Rondani, 1856

Genus: Drosophila Fallén, 1823

Drosophila replete Wollaston 1858

Drosophila repleta Wollaston, 1858.

Drosophila adspersa Mik, 1886.

Drosophila maculiventrisVan der Wulp, 1897.

Drosophila pygmaea Duda, 1927.

Drosophila austrorepleta Dobzhansky and Pavan, 1943.

\section{Diagnosis}

Small fly, approximately 3-3.5 mm in length; eyes dark red in color; palpi pale. Mesonotum with bristles and hairs each arising from a separate dark spot, these spots often fused together; coxae of the fore-legs heavily darkened in color. Abdomen brownish to black in color with distinctive yellow banding shading into brown along lateral margins of tergites.

\section{5- Family: Ephydridae Zetterstedt, 1837}

\section{Diagnosis}

Relatively small flies; varying from shiny black, gray or greenish metallic in color; body 1-5.5 mm in length; upper part of face projecting anteriorly; orbital setae lateroclinate; clypeus concealed; inner and outer vertical bristles well developed, shortened or vestigial; parafacial and frontal vitta setulose in some species and not in others; eyes widely separated; oral margin often ciliated. Legs generally long and slender; distal and proximal tarsal segments with long dense yellow hairs on the lower surface in the species that run on the water surface; notopleurae with two setae; anepisternum hairy and with 1-3 setae; mesopleuron with single large bristle; costa with two breaks; first radial vein ending before middle of wing; vein $\mathrm{R} 2+3$ long and terminating much closer to vein $R 4+5$ than to $R 1$; discal and second basal cells 
united; anal vein and anal cell absent. Abdomen mainly subconical, oval or elongate.

Subfamily: Gymnomyzinae Latreille, 1829

Genus: Chlorichaeta Becker, 1922

Chlorichaeta albipennis (Loew, 1848)

(Fig. 2b, c)

Gymnopa albipennis Loew, 1848.

Mosillus albipennis Schiner, 1863.

Chlorichaeta albipennis Cresson, 1925.

Chlorichaeta strandi Papp, 1979.

\section{Diagnosis}

Body varies from 1.5-2.8 mm in length. Scutellum with 3-5 pairs of large marginal setae on each side arising from distinct tubercles; disc of scutellum appearing granulose; halter dark brown to blackish brown; fore-tarsi black; hind basitarsomere blackish brown or brown in color.

6- Family: Fannidae Schnabl, 1911

\section{Diagnosis}

Small to medium sized robust flies; body and legs dark in color; second antennal segment distinctly grooved above; ptilinal suture clearly defined; maxillary palps 1 segmented; frontalia without crossed bristles in females; frontal orbits broad and convex towards median line of frons in females, two pairs of strong upper orbital bristles present. Thorax with dorsal suture continuous across the middle part, with well-developed posterior calli. Wings with well-developed lower calypter; axillary vein strongly curved towards the wing margin; hypopleural bristles absent; anal cell short and closed. Hind tibiae with strong bristles except the apical part.

\section{Remark}

Females of some species of genus Fannia attracted to carcasses where the larvae are necrophagous feeding on the decaying animal matters (Scudder and Canning, 2006). Fannia species are invading carcasses at an advanced stage of decomposition, which arrive to corpses after the blow flies and flesh flies.

The genus Fannia was originally considered to be a Muscidae, but now it is in the family Fannidae. (Dominguez, 2007).

Genus: Fannia Robineau-Desvoidy, 1830

Fannia sp.

\section{Diagnosis}

Small to medium in size; grayish or dark in color; eyes large and bare; proboscis short; arista plumose; female frontalia without cross bristles; frontal orbits broad convex towards the median line of frons with two pairs of strong upper orbital bristles. Anal vein very short not extending half the distance from its base to wing margin; axillary vein strongly curved. Mid tibia usually enlarged apically; hind tibia with a sub-median seta dorsally; male middle tibia with characteristic dense erect bubesence beneath.

\section{7- Family: Muscidae Latreille, 1802}

\section{Diagnosis}

Small to medium seldom largein size; gray or metallic green in color. Arista plumose throughout its length; frontal suture present. Calypters well developed; lower calypter nearly always longer than upper one; hypopleuron usually without bristles; more than one sternopleural bristle present. Vein $\mathrm{Cu} 1+1 \mathrm{~A}$ short not reaching margin of wing; vein $\mathrm{Sc}$ sinuous; Rs vein two-branched.

\section{Remark}

Family Muscidae comprises many synanthropic species, while others can breed on carrions, making some members of this family are important in estimation of post mortem interval (PMI) in criminal cases. This insect is coprophagous attracted to the carcasses rumen content (Carvalho \& Mello-Patiu, 2008).

Four muscid species were collected during our work, Musca domestica, Musca sorbens, Muscina stabulans and Synthesiomyia nudiseta. These species occurred during active decay stage of decomposition while Musca domestica were found earlier in bloated stage or late during advanced decay and skeletal stages.

Previously, genus Muscina was under subfamily Muscinae but now it become under subfamily Azeliinae (Couri, 2010).

\section{Key to subfamilies}

1- Anepimeron with setae or setulae on posterior half, directly above the hind katepisternal bristle.

.Muscinae Latreille.

- Anepimeron without setae or setulae. ...Azeliinae Robineau-Desvoidy.

1- Subfamily: Azeliinae Robineau-Desvoidy, 1830

\section{Key to genera}

1- Apical section of vein $M$ straight or only slightly curved forward (Fig. 2e); antennae gray to blackish in color (Fig. 2f).

....Muscina Robineau-Desvoidy.

-Apical section of vein $M$ strongly curved forward (Fig. 2g); antennae bright yellow orange in color 
(Fig. 2h)..... Synthe-

siomyia Brauer \& Bergenstamm

1- Genus: Muscina Robineau-Desvoidy, 1830

Muscina stabulans (Fallén, 1817)

(Fig. 2e, f, i)

Musca stabulans Fallen, 1817.

Muscina grisea Robineau-Desvoidy, 1830.

Musca stabulans Fallen, 1817.

Muscina grisea Robineau-Desvoidy, 1830.

Muscina picaena Robineau-Desvoidy, 1830.

Cyrtonevra australis Macquart, 1847.

Mydaea vomiturionis Robineau-Desvoidy, 1849.

\section{Diagnosis}

Body $8 \mathrm{~mm}$ in length; head ranges from whitish to darkgray in color. Antennae gray to blackish with first two segments and the base of third one red in color. Thorax with four dark stripes. Scutellum yellowish apically. Mesothoracic spiracle with brownish to black hairs.veinM1 +2 bend weakly upward meeting costa before wing apex. Tibia and apical half of femer yellowish in color, hind tibia with one strong posterodorsal seta in apical third. Abdomen entirely black or black with red sides; first abdominal sternite without differentiated bristles.

2- Genus: Synthesiomyia Brauer \& Bergenstamm, 1893 Synthesiomyia nudiseta (Van Der Wulp, 1883)

(Fig. 2g, h)

Cyrtoneura nudiseta Van der Wulp, 1883.

\section{Diagnosis}

Body about 7-10 $\mathrm{mm}$ in length, grayish in color. Antennae and palpi bright yellow orange in color; arista bare. Thorax striped; posterior spiracles with S-shaped slits; episternum without cilia; hypopleural bristles absent. Apical part of vein $M$ strongly curved forward. Abdomen gray with a patterns resembling checkerboard and somewhat tessellated with yellow color at apex.

2- Subfamily: Muscinae Latreille, 1802

Genus: Musca Linnaeus, 1758

\section{Key to species}

- Mesonotum with four dark stripes (Fig. 2l), proepisternal depression with fine setulae.

Musca domestica Linnaeus.

- Mesonotum with two dark stripes (in female devided in the form of $\mathrm{Y}$ in front of the suture) (Fig. $2 \mathrm{~m}$ ), proepisternal depression without setae.

.......Musca sorbens Wiedemann
1- Musca domestica Linnaeus, 1758

Musca domestica Linnaeus, 1758.

Sphora australis Robineau-Desvoidy, 1830.

Musca consanguinea Rondani, 1848.

Musca flavinervis Thomson, 1869.

Musca biseta Hough, 1898.

Musca divaricata Awati, 1916.

Degeeria obscura Pont, 1968.

\section{Diagnosis}

Medium-sized fly ranged from 6 to $9 \mathrm{~mm}$ in length; grayish in color with red eyes. $M$ (4th) vein sharply curved; humeral callus with 2-3 setae. Abdomen elongate pointed, in male yellowish in color with dark midline and some irregular dark markings on the sides, in female gray and black checkerboard patches.

\section{2- Musca sorbens Wiedemann, 1830}

Musca sorbens Wiedemann, 1830.

Musca humilis Wiedemann, 1830.

Musca bivittata Thomson, 1869.

Musca eutaeniata Bigot, 1888.

Musca promisca Awati, 1916.

Byomya alba Malloch, 1929.

\section{Diagnosis}

Small sized fly, ranged from 3 to $4.5 \mathrm{~mm}$ in length; grayish brown in color; frons broad; postalar ridge without setae. Mesonotum with gray pollinosity and two dark strips behind suture; meron setulose; anterior spiracle white or pale yellow. Mid tibia with four posterior setae.

8- Family: Phoridae, Curtis, 1833

\section{Diagnosis}

Small to very small flies; body $0.4-6.0 \mathrm{~mm}$ in length, gray-black or yellowish in color; eyes dichoptic in both males and females; ptilinal suture weakly defined or absent. Antennae 3-segmented; third antennal segment conceals the second one; arista may be dorsal or apical; palps often bear obvious bristles. Thorax with humped appearance in most species; mesopleuron with inverted L-shaped mesopleural furrow which present in the middle. Winged or wingless; wings without cross veins; costal and radial veins shortened and thickened; post radial veins fine and unforked; vein $\mathrm{M} 1+2$ unforked; Wings without discal, sub-apical and closed anal cells. Tibia often with isolated bristles away from the apical spurs; hind femora enlarged and flattened; hind legs long. Tergites only present on abdominal segments 1-6. 


\section{Remark}

Some adults of family Phoridae have forensic importance. They are necrophagous which feed on juices exuding from fresh carrion and dung (Campobasso, Disney, \& Introna, 2004). Phorid members infest carcasses at fresh stage from the day one post killing to the active decay stage of decomposition in the current work.

Subfamily: Metopininae Macquart, 1835

Genus: Megaselia Rondani, 1856

Megaselia scalaris (Loew, 1866)

(Fig. 3a, b)

Phora scalaris Loew, 1866.

Aphiochaeta banski Brues, 1909.

Aphiochaeta ferruginea Brunetti, 1912.

Aphiochaeta repicta Schmitz, 1915.

Lioyella plusiivorax Enderlein, 1929.

Megaselia forticapilla Beyer, 1959.

\section{Diagnosis}

Minute flies; body $0.2-0.3 \mathrm{~mm}$ in length; varying from, yellowish, brownish or blackish in color. Thorax yellowish to yellowish brown in color; thoracic bristles feathered. Wings usually large and fringed with short and long setae; halters clear yellow in color. Legs clear yellow, well developed, with stout enlarged hind femur which laterally compressed; tibia frequently composed of short closely set of setae. Abdomen with typically three to six tergites; yellowish brown in color, sometimes light but often darker, usually banded with brown patterns; abdomen sometimes wholly brown in males; females abdominal tergite six short, narrow, shiny and extends laterally on the segment, unlike the tergite of preceding segment.

\section{9- Family: Piophilidae Macquart, 1835}

\section{Diagnosis}

Relatively small and slender flies; body about $5 \mathrm{~mm}$ or less in length; most species metallic black usually with bluish reflection. Head rounded with rounded eyes; occiput region convex and prominent; vibrissae present; postvertical orbital bristles divergent. Antennae short in most species, third segment oval with arista arising dorsally near its base; ptilinal suture clearly defined. Lower calypter much reduced or absent. Subcosta with break; costa with interruption near subcosta close to R1; second basal and discal cells separated. Legs and abdomen never strongly bristled; post spiracular bristles absent. Abdomen broad basely.

\section{Remark}

Many species of family Piophilidae considered as necrophagous species breeding primarily during advanced stage of decomposition. Piophila casei considered as a potential indicator of the advanced stage of decay so, it has been reported to be an important forensic fly used in determination of PMI in homicide and suicide criminal cases (McAlpine, 1977 and Gennard, 2012). In the present study adults were observed in fresh, bloat and active decay stage of decomposition.

Subfamily: Piophilinae Fallén, 1810

Genus: Piophila Fallén, 1810

Piophila casei (Linnaeus, 1758)

Musca casei Linnaeus, 1758.

Musca atrata Fabricius, 1781.

Piophila petasionis Dufour, 1844.

Piophila melanocera Rondani, 1874.

Piophila smithii Hutton, 1901.

\section{Diagnosis}

Small flies, body 3-4.5 $\mathrm{mm}$ in length; usually black to bluish-black in color, lower part of head, antennae and parts of legs yellowish in color. Head with brownish eyes; palpi and proboscis usually bristled; checks prominent, distinctly more than half the eye height; ocellar bristle small and greatly separated; fronto-orbitals undeveloped. Antennae short. Wings iridescent, halteres pale yellow in color. Scutum with three distinct rows of setae (1 acrostichal and two dorsocentral); humeral, presutural, sternopleural bristles absent. Legs covered with short spines; hind trochanter of male with long pale ventral setae.

10- Family: Psychodidae Newman, 1834

\section{Diagnosis}

Small flies; 1-5 $\mathrm{mm}$ in length; body covered with hairs resembles tiny moth in appearance; ranged from yellow, gray to black in color. Long with 12-16 plumose flagellomers; antennal segments provided with sensory filaments (ascoids). Wing veins hairy and parallel without cross-veins in outer two-thirds of wing, except those forming basal cell in some species; costal vein surrounding the wing; vein A2 absent; wing bare or hairy.

Subfamily: Psychodinae Newman, 1834

Genus: Tinearia Schellenberg, 1803

Tinearia alternata (Say, 1824)

Psychoda alternata Say, 1824.

Psychoda sexpunctata Phillipi, 1865.

Psychoda albimaculata Welch, 1912.

Psychoda dakotensis Dyar, 1926.

Psychoda marmosa Abreu, 1930. 
Psychoda marmosa Abreu, 1930.

\section{Diagnosis}

Small stout flies, nearly $2 \mathrm{~mm}$ in length; yellowish in color; palpi of four segments. Wing veins with noticeable dark brown tufts of hairs at tips; basal cells shortened. Harpagones with blade shape laterally in males; subgenital plate U-shaped in female; genital chamber in female with a pair of posterior and a pair of dorsal projections.

\section{1- Family: Sarcophagidae Macquart, 1834}

\section{Diagnosis}

Medium to large in size; gray to grayish-black flies, some species yellow-gray, green-gray or almost entirely shiny black; body $8-14 \mathrm{~mm}$ in length usually stout and bristly; frontal suture present. Antennae 3-segmented, with arista commonly on basal half plumose in most species and bare in a few. Scutum with three black and gray vittae; calypters well developed; subscutellum concave narrow and flat, not swollen. Wing usually hyaline, infuscated anteriorly or ornamented with dark markings in some species; vein Rs 2-branched; vein $M_{1}$ always curving forward, sometimes ending in vein $R 4+5$ at the wing margin or before making cell $\mathrm{r}_{4+5}$ petiolate; meron always with bristles; Notopleura usually with four bristles (two strong and two small). Abdomen checkered, striped, banded or with spotted patterns.

\section{Remark}

Most flesh flies breed in dung and decaying materials, other certain species are necrophagous which they colonized in carrions. The necrophagous species used as forensic indicators to estimate postmortem intervals because they pervade carcasses at any stage of decomposition from recently dead, fresh stage, through to bloat or advanced decaying stages (Carvalho \& Mello-Patiu, 2008).

Three species only of family Sarcophagidae belonging to two subfamilies were collected Sarcophaga argyrostoma, Sarcophaga hertipes and Wohlfahrtia nuba. In the past, the first two species were included in the genus Parasarcophaga but currently they are considered in the genus Sarcophaga (Rognes, 1986), this confirmed by the structure and the form of male genitalia.

\section{Key to subfamilies}

1- Abdomen with patterns forming a median strip and dark lateral spots, coxopleural streak present, hind coxa bare on posterior surface Paramacronychiinae Brauer \& Bergenstamm

- Abdomen with distinct checkboard patterns, coxopleural streak absent, hind coxae with setae on posterior surface

\section{Brauer \& Bergenstamm}

1- Subfamily: Paramacronychiinae Brauer \& Bergenstamm, 1889

Genus: Wohlfahrtia Brauer \& Bergenstamm,1889

Wohlfahrtia nuba (Wiedemann, 1830)

Tachina nuba Wiedemann, 1830.

Wohlfahrtia volucris Seguy, 1941.

\section{Diagnosis}

Body medium in size; $5-12 \mathrm{~mm}$ in length; gray in color; second antennal segment and palps orange in color; frontal stripe dark gray with golden reflection, narrowed anteriorly. Middle femur with ventral surface has a comb of short thickened spines, ventral surface of mid and hind tibia of male without long hairs. Abdomen with black spots arranged in three longitudinal rows; fourth abdominal tergite with a bottle-neck extension reaching up to the anterior margin.

2- Subfamily: Sarcophaginae Brauer \& Bergenstamm, 1889

Genus: SarcophagaMeigen, 1826

\section{Key to species}

1- Circus rhomboidal in shape with nearly rounded apex, epandrium and circus with dense shorter hairs, postgonite and circus nearly subequal (Fig. 3e, f).........S. argyrostoma (Robineau-Desvoidy)

- Circus cylindrical in shape and pointed from apex, epandrium and circus with dispersal long hairs, postgonite nearly reach the half length of circus (Fig. 3g, h).... S. hertipes Weidemann

1- Sarcophaga argyrostoma (Robineau-Desvoidy, 1830)

(Fig. 3e, f, i)

Myophora argyrostoma Robineau-Desvoidy, 1830.

Sarcophaga barbata Thomson, 1869.

Sarcophaga argentina Brèthes, 1916.

Mesothyrsia henschiana Enderlein, 1928.

Ptilocnema henseliana Enderlein, 1928.

\section{Diagnosis: (male)}

Body 7-17 mm in length; silver gray or dusted yellowish white in color; palpi black in color; Palpi long and clearly broaden apically; genae with few black hairs near eyes; parafacial bristles short and weak, arranged in two longitudinal rows. Antennae black in color, first flagellomere about twice as long as pedicel. Lower calypters white in 
color. Wing hyaline; cell R5 open. Femora and hind tibiae with long dense hairs on ventral side. Abdomen rounded apically, abdominal segment $7+8$ lustrous brownish red or black in color and moderately elongate, with several hairs marginally. Male genitalia as in (Fig. 3e, f).

2- Sarcophaga hertipes Weidemann, 1830

(Fig. 3g, h, j)

\section{Diagnosis: (male)}

Body 7-16 mm in length; palpi yellow; genae with numerous black anteriorly; three rows of black postocular setae present; only first row regular. Mid femur with comb-like posteroventral bristles on apical part; hind femur with fringe, hind tibia usually fringed without anteroventral bristles; acrostichal bristles $0+1+1$. Abdomen pointed apically. Ventralia pedunculated; fourth sternite sparsely haired; stylus slender, never covered with microscopic hair; propleuron bare. Male genitalia as in (Fig. 3g, h).

\section{2- Family: Sphaeroceridae Macquart, 1835}

\section{Diagnosis}

Minute to small rather robust flies; body $0.7-5.5 \mathrm{~mm}$ in length; usually dull flies ranged from brown to blackish in color, sometimes with yellow, orange or reddish head, thorax and legs with markings on them. Lateral view of face excavated deeply between antennae and the edge of mouth; ptilinal suture clearly defined; maxillary palps 1 segmented; vibrissae present. Arista long bare to pubescent; second antennal segment not grooved. Thorax without continuous dorsal suture on scutum and without well-defined posterior calli. Winged or wingless; costa with two breaks; lower calypter reduced or absent. Hind leg with basitarsus swollen and shorter than the second.

Subfamily: Limosininae Frey, 1921

Genus: Pullimosina Roháček, 1983

Pullimosina heteroneura (Haliday, 1836)

Limosina heteroneura Haliday, 1836.

Limosina jeanneli Bezzi, 1911.

Leptocera rara Spuler, 1925.

Leptocera opaca Aldrich, 1932.

Leptocera opacella Richards, 1961.

\section{Diagnosis}

Small species with dark colored body; about $3-4 \mathrm{~mm}$ in length, having shortened discal cell, with section on $M$ between anterior $(\mathrm{r}-\mathrm{m})$ and posterior $(\mathrm{dm}-\mathrm{cu})$ cross veins distinctly shorter than posterior cross-vein.

\section{3-Family: Ulidiidae Macquart, 1835}

\section{Diagnosis}

Medium seized insects, body commonly 4-7 $\mathrm{mm}$ in length; moderately elongated; diversely colored, yellow, brown or black in color with patterns of microtrichose bands; often with metallic blue or green luster. Head with Post-vertical orbital bristles which parallel or divergent; frontal setae absent in most species; vibrissa absent. Thorax longer than broad. Wing variable in shape, in most species with patterns of dark spots; subcostal vein complete; costal vein with distinct humeral break; cup cell usually pointed and extended to posterior apex. Legs usually without rows of strong setae. Females with well-developed telescopic ovipositor consisting of fused tergosternum seven; male tergite six lacking or rudimentary.

\section{Remark}

Family Ulidiidae was reported as insects associated with carcasses for the first time in Egypt during the present study. This family comprised only one species, Physiphora alceae, their larvae are necrophagous which seen on carcasses at bloat, active decay and advanced decay decompositional stages.

Subfamily: Ulidiinae Macquart, 1835

Genus: Physiphora Fallén, 1810

Physiphora alceae (Preyssler, 1791)

Musca alceae Preyssler, 1791.

Musca demandata Fabricius, 1798.

\section{Diagnosis}

Small seized fly; body $3-4 \mathrm{~mm}$ in length, shiny metallic green or blue-black in color; head mostly orange-brown in color; palpi orange to black; first flagellomere orange; arista orange to brown in color; eye with colored striped appearance; ptilinal suture clearly defined; frons slightly concave, with two lateral microtrichose spots. Thorax mostly metallic green except scutellum shiny goldengray in color, densely shagreened. Four apical tarsomeres of fore tarsus black in color and basal segment white to yellow in color; femora and tibiae brown to black; thorax with 1 acrostichal setula and one to two anepisternal setae. Veins yellow to orange in color; vein $\mathrm{R} 4+5$ almost or completely closed. Abdomen shiny black with bluegreen shade. Tergites 1-4 smooth, fifth tergite densely shagreened.

\section{Conclusions}

Throughout this work 23 dipterous species within 13 families were taxonomically studied. These species were identified and listed as follow. 
1-Family: Calliphoridae (six species)

Calliphora vicina, Chrysomya albiceps, Chrysomya megacephala, Chrysomya rufifacies, Lucilia sericata and Lucilia cuprina.

2- Family: Sarcophagidae (three species)

Sarcophaga argyrostoma, Sarcophaga hertipes and Wohlfahrtia nuba.

3-Family: Muscidae (four species)

Musca domestica, Musca sorbens, Muscina stabulans and Synthesiomyia nudiseta.

4-Family: Fannidae (one species)

Fannia sp.

5-Family: Phoridae (one identified species and another unidentified)

Megaselia scalaris.

6-Family: Piophilidae (one species)

Piophila casei.

7- Family: Ulidiidae (one species)

Physiphora alceae.

8- Family: Sphaeroceridae (one species)

Pullimosina heteroneura.

9- Family: Drosophilidae (one species)

Drosophila repleta.

10- Family: Psychodidae (one species)

Tinearia alternata.

11- Family: Ephydridae (one species)

Chlorichaeta albipennis.

12- Family: Dolichopodidae (one species)

Medetera sp.

13- Family: Agromyzidae (one species).

Phytomyza sp.

Through the previous research in Egypt there were no any taxonomic studies related to insects of forensic importance. Accordingly, the present work was carried out to provide a brief taxonomic study to the adult insects of forensic importance of order Diptera to facilitate the identification of them for evaluation of PMI in criminal investigations.

\section{Acknowledgements}

My grateful thanks are passed to the staff members of Entomology Department, Faculty of Science, Ain Shams University and also to the staff members of Faculty of Science, Cairo University for their kind help.

\section{Funding}

This study was not funded from any institution or any other entity.

\section{Availability of data and materials}

Not applicable

\section{Authors' contributions}

RS participated in the practical part and in the sequence alignment and drafted the manuscript. $\mathrm{HH}$ dissected and photographed the specimens and participated in the sequence alignment. RH participated in the practical part and helped to draft the manuscript. All authors conceived of the study, read, and approved the final manuscript.

\section{Authors' information}

- RS: Assistant professor, Entomology Department, Faculty of Science, Ain Shams University.

- HH: Professor of insect taxonomy, Entomology Department, Faculty of Science, Ain Shams University.

- RH: Assistant Lecturer, Entomology Department, Faculty of Science, Ain

Shams University.

Ethics approval and consent to participate

All applicable international, national, and/or institutional guidelines for the care and use of animals were followed.

\section{Consent for publication}

Not applicable

\section{Competing interests}

The authors declare that they have no competing interests.

\section{Publisher's Note}

Springer Nature remains neutral with regard to jurisdictional claims in published maps and institutional affiliations.

Received: 3 June 2017 Accepted: 5 January 2018

Published online: 02 February 2018

\section{References}

Al-Ghamdi, K. M., Alikhan, M., Mahyoub, J. A., Alanazi, N. A., Al-Najada, A. R. Nassar, M. I., \& Alfarhan, B. Z. (2015). Characterization of forensically important Necrophagus flies (Diptera) of Jeddah, Saudi Arabia. Advances in Environmental Biology, 9(8), 58-71.

Bickel, D. J. (1985). A revision of the Nearctic Medetera (Diptera: Dolichopodidae). Technical Bulletin United States Department of Agriculture, 1692, 1-109.

Bickel, D. J. (2013). The family Dolichopodidae (Diptera) of the Pilbara region, Western Australia in its Australasian biogeographic context, with the description of 19 new species. Records of the Western Australian Museum, 83, 291-348.

Brown, B. V.; Borkent, A.; Cumming, J. M.; Wood, D. M.; Woodley, N. E. and Zumbado, M. A. (2009): Manual of central American Diptera, Vol (1). NRC Research Press, Ottawa. 714 pp.

Brown, B. V., \& Horan, R. V. (2012). A key to Neotropical region frog-egg-feedig species of Megaselia (Diptera: Phoridae), with a new species from Panama. Contribution Science, 520, 1-4.

Campobasso, C. P., Disney, R. H. L., \& Introna, F. (2004). A case of Megaselia sclaris (Loew) (Diptera, Phoridae) breeding in a human corpse. Aggrawal's Internet Journal of Forensic Medicine and Toxicology, 5(1), 3-5.

Carles-Tolrá, M. (2011). Some dipterans collected on winter cadavers in La Rioja (Spain) (Diptera: Phoridae, Heleomyzidae and Sphaeroceridae). Boletín de la Sociedad Entomológica Aragonesa, 48, 147-150.

Carvalho, C. J. B., \& Mello-Patiu, C. A. (2008). Key to the adults of the most common forensic species of Diptera in south American. Brazilian Journal of Entomology, 52(3), 390-406.

Chen, X. L., \& Kameneva, E. P. (2007). A review of Physiphora Fallén (Diptera: Ulidiidae) from China. Zootaxa, 1398, 15-28.

Couri, M. S. (2007): A key to the Afrotropical genera of Muscidae (Diptera). Rev. Bras. Zool. vol. (1): 175-184.

Couri, M. S. (2010). Key to the Australasian and Oceanian genera of Muscidae (Diptera). Brazilian Journal of Entomology, 54(4), 529-544.

Couri, M. S., Carvalho, C. J. B., \& Pont, A. C. (2012). Taxonomy of the Muscidae (Diptera) of Namibia: A key to genera, diagnoses, new records and description of a new species. African Invertebrates, 53(1), 47-67.

Disney, R. H. L. (1983): Scuttle flies. Diptera, Phoridae (except Megaselia). Handbooks for the identification of British insects, Vol. 10, part 6. London: Royal Entomological Society of London. 81pp.

Dominguez, M. C. (2007). A taxonomic revision of the southern south American species of the genus Fannia Robineau-Desvoidy (Diptera: Fanniidae). Roles of Zoology, 47(24), 289-347.

Draber-Monko, A., Malewski, T., Pomorski, J., Łos, M., \& Ślipinski, P. (2009). On the morphology and mitochondrial DNA Barcoding of the flesh fly Sarcophaga (Liopygia) argyrostoma (Diptera: Sarcophagidae)-an important species in forensic entomology. Annales Zoologici (Warszawa), 59(4), 465-493. 
Ebrahim, A. M., \& Salem, M. M. (2010). An illustrated key to the families of order Diptera as known to occur in Egypt. Egyptian Academy Journal Biological Science, 3(1), 57-79.

Emden, F. I. (1954). Diptera Cyclorrhapha Calyptrata (i) section (a) Tachinidae and Calliphoridae. Handbooks for the identification of British insects. Royal Entomological Society London, 10(4a), 133.

Gennard, D. (2012): Forensic Entomology: An Introduction. John Wiley \& Sons. 67 pp -. ISBN 978-1-119-94543-7.Retrieved 13 April 2013.

Haarto, A., \& Kahannpää, J. (2013). Notes on Finnish Sphaeroceridae (Diptera) with description of the female of Minilimosina tenera Rohacek, 1983. Entomologica Fennica, 24, 228-233.

Harrison, R. A. (1959). Acalypterate Diptera of New Zealand. Bulletin New Zealand Department Science Industrial Research., 128, 1-382.

Huckett, H. C. (1975). The Muscidae of California exclusive of subfamilies Muscinae and Stomoxyinae. Bulletin California Insect Survey, 18, 1-148.

James, M. T. (1947): The flies that cause myiasis in man. USDA Misc. Publ. No. 631: 1-175

James, M. T. (1971). Genus Chrysomya in new Guinea (Diptera: Calliphoridae). Pacific Insect, 13(2), 361-369.

Ježek, J. (1977). Reinstatement of the genus Tinearia Schellenberg (Diptera, Psychodidae). Acta Entomologica Bohemoslovaca, 74, 232-241.

Ježek, J.; Le Pont, F.; Martinez, E. and Mollinedo, S. (2011): Three new species of non-biting moth flies (Diptera: Psychodidae: Psychodinae) from Bolivia, with notes on higher taxa of the subfamily. Acta Entomologica Musei Natioalis Pragae, 51: 183-210.

Kavazos, C. R. J., \& Wallman, J. F. (2012). Community composition of carrionbreeding blowflies (Diptera: Calliphoridae) along an urban gradient in southeastern Australia. Landscape and Urban Planning., 106(2), 183-190.

Keshavarzi, D., Fereidooni, M., Assareh, M., \& Nasiri, Z. (2015). A checklist of forensic important flies (Insecta: Diptera) associated with indoor rat carrion in Iran. Journal of Entomology and Zoology Studies, 3(3), 140-142.

Kosmann, C., Pinto de Mello, R., Harterreiten-Souza, É. S., \& Pujol-Luz, J. R. (2013). A list of current valid blow fly names (Diptera: Calliphoridae) in the Americas south of Mexico with key to the Brazilian species. Entomol Brasil, 6(1), 74-85.

Kurahashi, H., Benjaphong, N., \& Omar, B. (1997). Blow flies (Insecta: Diptera: Calliphoridae) of Malaysia and Singapore. Raffles Bulletin Zoology, (Suppl 5), 1-88.

Lopes, H. D. S. (1961). Hawaiian Sarcophagidae (Diptera). Proceedings Hawaiian Entomology Society, 17(3), 419-427.

Marshall, S. A.; Rohacek, J.; Dong, H. and Buck, M. (2011): The state of Sphaeroceridae (Diptera: Acalyptratae): A world catalog update covering the years 2000-2010, with new generic synonymy, new combinations, and new distributions. Acta Entomologica Musei Natioalis Pragae 51(1): 217-298.

Marshall, S. A., Whitworth, T., \& Roscoe, L. (2011). Blow flies (Diptera: Calliphoridae) of eastern Canada with a key to Calliphoridae subfamilies and genera of eastern North America, and a key to the eastern Canadian species of Calliphorinae, Luciliinae and Chrysomyiinae. Canadian Journal Arthropod Identification., 11, 1-93.

McAlpine, J. F. (1977). A revised classification of the Piophilidae, including "Neottiophilidae" and "Thyreophoridae" (Diptera: Schizophora). The Memoirs of the Entomological Society of Canada, 103, 1-66.

Morgulis, E., \& Freidberg, A. (2014). The Ulidiini (Diptera: Tephritoidae: Ulidiidae) of Israel, with a key to the world species of Ulidia and description of five new species. Zootaxa, 3780(2), 201-247.

Nihei, S. S., \& Barros De Carvalho, C. J. (2009). The Muscini flies of the world (Diptera, Muscidae): Identification key and generic diagnoses. Zootaxa, 1976, 1-24.

Oldroyd, H. (1954): Handbooks for the identification of British insects. Roy. Enomol. Soc. handbooks, Vol. IX, part 1. Diptera. 1. Introduction and key to families. 49pp.

Peter, J. M. (2007). Why are there so many insect species? Perspectives from fossils and phylogenies. Biological Reviews, 82(3), 425-454.

Povolný, D., \& Verves, Y. (1997). The flesh-flies of Central Europe (Insecta, Diptera, Sarcophagidae). Spixana, 24, 1-260.

Rochefort, S., Giroux, M., Savage, J., Wheeler, T. A. (2015): Key to Forensically Important Piophilidae (Diptera) in the Nearctic Region. Canadian J. Arthrop. Ident. No. 27.

Rognes, K. (1986). The Sarcophagidae (Diptera) of Norway. Fauna Norvegica (Ser. B), 33, 1-26.

Rohácek, J. (2011). The fauna of Sphaeroceridae (Diptera) in the Gemer area (Central Slovakia). Casopis slezského zemského muzea (A), 60, 25-40.

Rohácek, J. (2013): The fauna of Acalyptrate families Trixoscelididae, Chyromyidae and Sphaeroceridae (Diptera) in the Gemer area (Central Slovakia): Supplement 2. Casopis Slezského Zemského Muzea (A), 62: 155-172.
Scudder, G.G.E. and Cannings, R.A. (2006): The Diptera families of British Columbia. Columbia University: 1-163.

Shahid, S. A., Hall, R. D., Haskell, N. H., \& Merritt, R. W. (2000). Chrysomya rufifacies (Macquart) (Diptera: Calliphoridae) established in the vicinity of Knoxville, Tennessee, USA. Journal of Forensic Science, 45(4), 896-897.

Sharma, R., Garg, R. K., \& Gaur, J. R. (2015). Various methods for the estimation of the post mortem interval from Calliphoridae: A review. Egyptian Journal of Forensic Science, 5(1), 1-12.

Spencer, K. A. (1972). Diptera : Agromyzidae. Handbooks for the identification of British insects, (vol. 10, p. 136). London: Roy. Entomol. Soc.

Spencer, K. A. (1977). A revision of the Australian Agromyzidae (Diptera). Special publication. Western Australian Museum, 8, 1-255.

Szpila, K. (2012): Key for identification of European and Mediterranean blowflies (Diptera, Calliphoridae) of forensic importance adult flies. In forensic entomology, an introduction, $2^{\text {nd }}$ edition, ed. D. Gennard, west Sussex, United Kingdom: Willy-Blackwell: 77-81 + plates 5.1-5.9.

Unwin, D. M. (1981). A key to the families of British Diptera. Journal of Field Studies Council., 5, 513-533.

Vairo, K. P., Mello-Patiu, C. A., \& Carvalho, C. J. B. (2011). Pictorial identification key for species of Sarcophagidae (Diptera) of potential forensic importance in southern Brazil. Revista Brasileira de Entomologia, 55(3), 333-347.

Vilela, C. R. (1983): A revision of the Drosophila repleta species group (Diptera, Drosophilidae). Brazilian Society of Entomology. 114pp.

Williams, K. A., \& Villet, M. H. (2014). Morphological identification of Lucilia sericata, Lucilia cuprina and their hybrids (Diptera, Calliphoridae). Zookeys, 420, 69-85.

\section{Submit your manuscript to a SpringerOpen ${ }^{\circ}$ journal and benefit from:}

- Convenient online submission

- Rigorous peer review

- Open access: articles freely available online

- High visibility within the field

- Retaining the copyright to your article

Submit your next manuscript at springeropen.com 